\title{
Platelet Concentrates: Past, Present and Future
}

\author{
Shobha Prakash • Aditi Thakur
}

Received: 20 April 2010/ Accepted: 30 January 2011/Published online: 25 February 2011

(C) Association of Oral and Maxillofacial Surgeons of India 2011

\begin{abstract}
Platelets play a crucial role in hemostasis and wound healing, platelet growth factors are well known source of healing cytokines. Numerous techniques of autologous platelet concentrates have been developed and applied in oral and maxillofacial surgery. This review describes the evolution of the first and second generation of platelet concentrates (platelet rich plasma and platelet rich fibrin respectively) from their fore runner-fibrin sealants.
\end{abstract}

Keywords Platelet rich plasma - Platelet rich fibrin . Fibrin sealants · Platelet growth factors .

Wound healing

\section{Introduction}

Among the great challenges facing clinical research is the development of bioactive surgical additives regulating inflammation and increasing healing [1].The healing of hard and soft tissue is mediated by a wide range of intra and extracellular events that are regulated by signaling proteins. Understanding the entire process is still incomplete. However, it is known that platelets play a crucial role not only in hemostasis, but also in the wound healing process [2].

S. Prakash $(\square)$

Department of Periodontics, College Of Dental Sciences, Room

No 4, Davangere, Karnataka 577004, India

e-mail: shobhaprakash5@yahoo.com

A. Thakur

College Of Dental Sciences, Davangere, Karnataka 577004,

India
Platelets are anucleate cytoplasmic fragments derived from bone marrow megakaryocytes and measure 2-3 $\mu \mathrm{m}$ in diameter. They contain many granules, few mitochondria and 2 prominent membrane structures, the surfaceconnected canalicular system and the dense tubular system. The $\alpha$ granules are spherical or oval structures with diameters ranging from 200 to $500 \mathrm{~nm}$ each enclosed by a unit membrane. They form an intracellular storage pool of proteins vital to wound healing, including platelet-derived growth factor (PDGF), transforming growth factor (TGF$\beta$ ), and insulin-like growth factor (IGF-I). The $\alpha$ granules fuse with the platelet cell membrane after activation. At least some secretory proteins are transformed to a bioactive state. The active proteins are then secreted, allowing them to bind to transmembrane receptors of the target cells. Once bound, intracellular signal proteins are activated. This results in the expression of a gene sequence that directs cellular proliferation, collagen synthesis, osteoid production, and so on [2].

Platelet growth factors are a well-known source of healing cytokines, usable for clinical applications. Numerous techniques of autologous platelet concentrates have been developed and applied in oral and maxillofacial surgery. These techniques finally lead to a fibrin and platelet concentrate for topical application. Blood is collected with anticoagulant, then centrifuged (often a 2-step centrifugation) in order to discard the red blood cells and a part of the useless acellular plasma, and to collect mainly a base of platelets. The latter are placed again in solution in some plasma (rich in fibrinogen), then injected on the surgical site, most often in the presence of calcium and bovine thrombin (triggering polymerization of fibrinogen into fibrin and platelet activation) [3].

This review describes the evolution of the first and second generation of platelet concentrates (platelet rich 
plasma and platelet rich fibrin respectively) from their fore runner-fibrin sealants.

\section{Fibrin Sealants (FS)}

The first surgical additives to be used were fibrin sealantscommercially available in Europe since late 1970s. Fibrin sealants, 'fibrin glues' or fibrin tissue adhesives are human plasma derivatives that mimic the final stages of blood coagulation, forming a fibrin clot. They are used for topical hemostasis and tissue sealing and as melting agents for particulate bone substitutes. Risk of cross infection for commercial adhesives (Tisseel, Baxter healthcare) led to the development of autologous fibrin sealants from the patient's own plasma. However, their fabrication resulted in less reproducible or less satisfactory rheologic properties [4].

Types of Fibrin Sealants, (FS)

(1) Homologous (commercial) FS: these are available as freeze dried two component preparations:

- A fibrinogen/fibronectin/factor XIII concentrate dissolved in an antifibrotic solution (usually aprotinin).

- Thrombin concentrate dissolved in dilute calcium chloride.

Mixing of the 2 components mimics the last stage of the coagulation cascade resulting in a fibrin clot independent of the patient's coagulation pathway. The fibrinogen component contains factor XIII, and the thrombin component contains calcium $\left(\mathrm{Ca}^{++}\right)$ions. Factor XIII, activated by thrombin in the presence of $\mathrm{Ca}^{++}$ions, catalyses cross linking between the fibrin molecules, resulting in a cross linked insoluble fibrin matrix.

Homologous fibrinogen concentrates are prepared from plasma cryoprecipitate or from Cohn fraction I.

(2) Autologous FS: Due to risk of transmitting infectious agents fibrin sealants were prepared from patient's own whole plasma. Fibrin polymerization is always initiated with bovine thrombin.

Indications [11]

- When esthetics is critical.

- When patients need to travel long for suture removal.

- Hemostasis.

- To seal the gingival margin after soft tissue augmentation.
Clinical Applications in Dentistry

- Treatment of intrabony defects [5].

- Alveolar ridge augmentation [6].

- Treatment of recession [7-9].

- Bone regeneration involving dental implants [10].

- Sinus floor augmentation [10].

- Treatment of extraction wounds [11].

Limitations

- Composition and the characteristics of the sealants (commercial, homologous, autologous) varies [4].

- Autologous fibrin sealants are generally weaker and have lower resistance to physical stresses than commercial sealants [4].

- The beneficial effects of fibrin sealants for soft tissues are well documented, yet their contribution to bone surgery and periodontal surgery remains controversial [4].

- Fibrin glue requires either pre donation or costly processing of autologous blood or the use of homologous blood products which may be associated with a risk of viral transmission [12].

\section{Platelet Rich Plasma-First Generation Platelet Concentrates}

The use of autologous products with high platelet concentrations such as Platelet rich plasma (PRP), Platelet concentrates (PC) and platelet gels developed to combine the fibrin sealant properties with growth factor effects of platelets-providing an ideal growth factor delivery system at the site of injury. The scientific rationale behind the use of these preparations lies in the fact that growth factors (GFs) are known to play a crucial role in hard and soft tissue repair mechanisms [13-16]. These GFs exhibit chemotactic and mitogenic properties that promote and modulate cellular functions involved in tissue healing, regeneration and cell proliferation [17].

\section{Technique}

- Venous blood is taken with anticoagulant to avoid platelet activation and degranulation.

- The first centrifugation ("soft spin") allows the blood separation in 3 distinct layers.

- Using a sterile syringe, the practitioner aspirates platelet poor plasma (PPP), platelet rich plasma (PRP), and some red blood corpuscles (which are systematically attracted during the operation).Then the 
material is transferred to another tube, without anticoagulant.

- This second tube will undergo another centrifugation, purported to be longer and faster than the first ("hard spin"). This makes it possible to concentrate platelets at the bottom of the tube and subsequently to obtain once again 3 distinct layers.

- At this stage, it becomes easy to collect the PRP. With a syringe, the practitioner can discard the major part of the PPP, leaving just enough serum to place the concentrated platelets in suspension. The unit is then gently shaken to obtain a ready-to-use cPRP (concentrated platelet rich plasma).

- cPRP is then mixed with bovine thrombin and calcium chloride at the time of application, with the help of a mixing syringe. Gelling of platelet concentrate will then quickly occur: Fibrinogen is also concentrated during the cPRP preparation, and its polymerization will constitute a fibrin matrix with particularly interesting hemostatic and adhesive properties [1].

\section{Clinical Applications [18]}

- In sinus lift procedures.

- Ridge augmentations.

- Socket preservation.

- Alveolar cleft palate repair.

- Oral/nasal fistula repair.

- Intra bony defects.

- Jaw reconstruction surgeries.

- Soft tissue procedures like-gingival grafts, subepithelial grafts, etc., because of its property of increasing soft tissue healing.

\section{Advantages of Platelet Gel and PRP Over Fibrin} Sealants [12]

- Safe autogenous preparation, free from concerns over transmissible diseases such as HIV, hepatitis, West Nile fever and Creutzfeld-Jacob disease (mad cow disease).

- Convenient for patient since blood is collected in the immediate preoperative period.

- More patients are eligible for this procedure because the criteria of blood bank donation do not have to be met, this would include children upto age 6 , weights upto $25 \mathrm{~kg}$, the elderly, those whose medical condition would preclude the blood bank from drawing a unit of whole blood.

- Presence of platelets brings cytokines and growth factors to the site of surgery in a manner that would not occur with fibrin glue.
Limitations [19]

- Concern over the use of bovine thrombin, bovine factor $\mathrm{Va}$ maybe a contaminant in certain bovine thrombin commercial preparations, antibodies to bovine factor $\mathrm{Va}$ may cross react with human factor $\mathrm{Va}$ and may produce coagulopathies and rare bleeding episodes.

- Lack of uniformity in PRP preparation protocol as different platelet concentrations have different storage time.

\section{Platelet Rich Fibrin (PRF)—Second Generation Platelet Concentrate}

Platelet rich fibrin (PRF) was first developed in France by Choukroun et al. in 2001. This second generation platelet concentrate eliminates the risk associated with the use of bovine thrombin [20].

The PRF protocol is very simple: A blood sample is taken without anticoagulant in $10-\mathrm{ml}$ tube which is immediately centrifuged in a table centrifuge at 3,000 rpm (approximately $400 \mathrm{~g}$ ) for $10 \mathrm{~min}$ [1].

The absence of anticoagulant implies the activation in a few minutes of most platelets of the blood sample in contact with the glass tube walls and the release of the

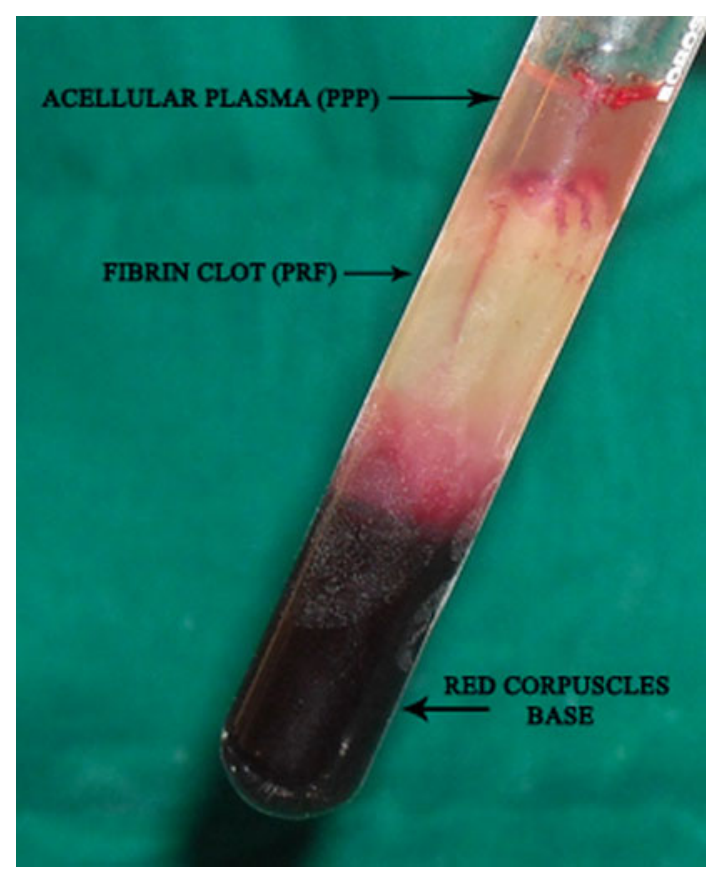

Fig. 1 Blood processing with a tabletop centrifuge (REMY Laboratories) allows the composition of structured fibrin clot in the middle of the tube, between the red blood cells at the bottom and acellular plasma at the top 


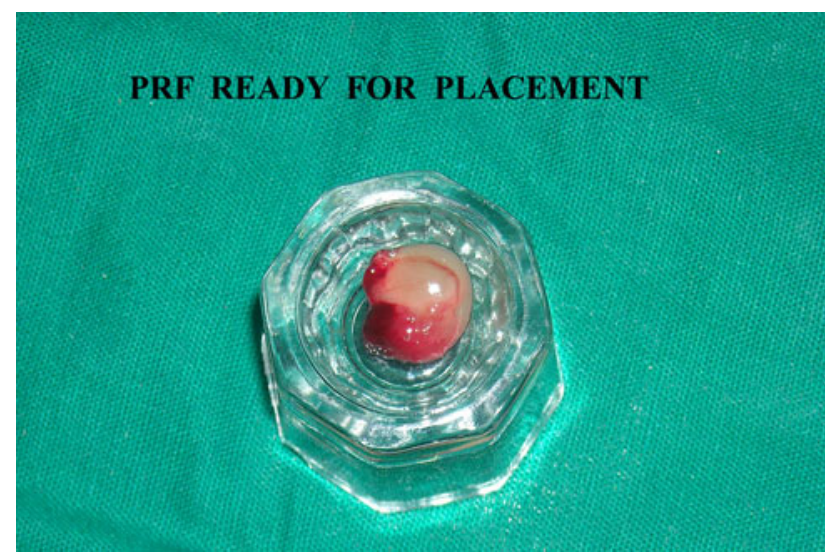

Fig. 2 PRF separated from PPP and RBC layer, ready for placement as a graft alone or in combination with bone graft

coagulation cascades. Fibrinogen is initially concentrated in the high part of the tube, before the circulating thrombin transforms it into fibrin. A fibrin clot is then obtained in the middle of the tube, just between the red corpuscles at the bottom and acellular plasma at the top (Fig. 1).

The success of this technique entirely depends on the speed of blood collection and transfer to the centrifuge. Quick handling is the only way to obtain a clinically usable PRF clot (Fig. 2). If the duration required to collect blood and launch centrifugation is overly long, failure will occur: The fibrin will polymerize in a diffuse way in the tube and only a small blood clot without consistency will be obtained (Table 1) [1].

\section{Properties of PRF}

(1) The biochemical analysis of the PRF composition indicates that this biomaterial consists of an intimate assembly of cytokines, glycanic chains, structural glycoproteins enmeshed within a slowly polymerized fibrin network. These biochemical components have well known synergetic effects on healing processes [21].

(2) PRF is not only a platelet concentrate but also an immune node able to stimulate defense mechanisms. It is likely that the significant inflammatory regulation noted on surgical sites treated with PRF is the outcome of retro control effects from cytokines trapped in the fibrin network and released during the remodeling of this initial matrix [22].

(3) Role of fibrin matrix of PRF:

- Fibrin is the natural guide of angiogenesis.

- Fibrin constitutes a natural support to immunity.

- Fibrin and wound coverage: Fibrin matrix guides the coverage of injured tissues, affecting the metabolism of epithelial cells and fibroblasts [23].

\section{Clinical Implications of PRF}

- In sinus lift procedures [7].

- Socket preservation [18].

- PRF membrane has been used for gingival recession coverage with coronally advanced or lateral pedicle flap for multiple and single recession respectively. PRF acts both as healing and interpositional biomaterial $[18,21$, 22].

- Filling of cystic cavity [7].

- In the treatment of combined periodontic endodontic lesion/furcation defect [23].

\section{Advantages of PRF over PRP}

- No need of addition of bovine thrombin or other anticoagulants so it is completely safe.

- Standard production protocol.

Difference between first and second generation platelet concentrates [1]

\begin{tabular}{lc}
\hline First generation-cPRP & Second generation-PRF \\
\hline $\begin{array}{l}\text { Use of bovine thrombin and calcium chloride } \\
\text { (anticoagulants) }\end{array}$ & No anticoagulants used \\
$\begin{array}{l}\text { Sudden fibrin polymerization-depending on the amount of } \\
\text { surgical additives (thrombin and calcium chloride) }\end{array}$ & $\begin{array}{c}\text { Slow natural polymerization on contact with glass particles of the test } \\
\text { tube results in physiologic thrombin concentration }\end{array}$ \\
$\begin{array}{l}\text { 3-D organization of a fibrin network-condensed tetra } \\
\text { molecular or bilateral junctions constituted with strong } \\
\text { thrombin concentrations, allows the thickening of fibrin } \\
\text { polymers: this leads to a rigid network, not very favorable } \\
\text { to cytokine enmeshment and cellular migration }\end{array}$ & $\begin{array}{c}\text { 3-D network-connected trimolecular or equilateral junctions-allows } \\
\text { the establishment of a fine and flexible fibrin network able to support } \\
\text { cytokines enmeshment and cellular migration }\end{array}$ \\
$\begin{array}{l}\text { The 3-D structure provides great resistance of such a gel, } \\
\text { appropriate to firmly seal biologic tissues }\end{array}$ & The 3-D structure gives elasticity and flexibility to the PRF membrane \\
\hline
\end{tabular}


Limitations of PRF Technology

(1) Only a limited volume of PRF can be used. Because it is obtained from an autologous blood sample, the quantities produced are low. This fact limits the systematic utilization of PRF for general surgery.

(2) PRF tissue banks are unfeasible. The fibrin matrix contains all the circulating immune cells and all the highly antigenic plasmatic molecules. That is why PRF membranes are totally specific to the donor and cannot constitute an allogenic graft tissue [23].

\section{Conclusion}

Despite the evident clinical advantages of fibrin sealants and platelet rich plasma, evidence of their beneficial actions is still lacking, hence there is a requirement for the justification of their widespread use. Additional randomized, controlled clinical trials are warranted to test the long term benefits and ultimate surgical outcomes associated with PRP and FS $[2,17]$. As with PRF, though this biomaterial appears to accelerate physiologic healing, the numerous perspectives of PRF have still to be clinically tested [1].

\section{References}

1. Dohan DM, Choukroun J, Diss A, Dohan SL, Dohan AJ, Mouhyi $\mathrm{J}$ et al (2006) Platelet-rich fibrin (PRF): a second-generation platelet concentrate. Part I: technological concepts and evolution. Oral Surg Oral Med Oral Pathol Oral Radiol Endod 101:e37-e44

2. Gasling VLW, Acil Y, Springer IN, Hubert N, Wiltfag J (2009) Platelet-rich plasma and platelet-rich fibrin in human cell culture. Oral Surg Oral Med Oral Pathol Oral Radiol Endod 108:45-48

3. Dohan Ehrenfest DM, Diss A, Odin G, Doglioli P, Hippolyte MP, Charrier JB (2009) In vitro effects of Choukroun's PRF on human gingival fibroblasts, dermal prekeratinocytes, preadipocytes, and maxillofacial osteoblasts in primary cultures. Oral Surg Oral Med Oral Pathol Oral Radiol Endod 108(3):341-352

4. Soffer E, Ouhayoun JP, Anagnostou F (2003) Fibrin sealants and platelet preparations in bone and periodontal healing. Oral Surg Oral Med Oral Pathol Oral Radiol Endod 95:521-528

5. Becker W (2008) Fibrin sealants in implant and periodontal treatment: case presentations. Compend Contin Educ Dent 29(3):182-185

6. Hellem S, Astrand P, Stenstrom B et al (2003) Implant treatment in combination with lateral augmentation of the alveolar process: a 3 year prospective study. Clin Implant Dent Relat Res 5: 233-240
7. Trombelli L, Scabbia A, Carotta V et al (1996) Clinical effect of subgingival tetracycline irrigation and tetracycline loaded fiber application in the treatment of adult periodontitis. Quintessence Int 27:19-25

8. Trombelli L, Scabbia A, Wikesjo UM et al (1996) Fibrin glue application in conjunction with tetracycline root conditioning and coronally positioned flap procedure in the treatment of human gingival recession defects. J Clin Periodontol 23:861-867

9. Trombelli L, Schincaglia GP, Zangari F et al (1995) Effect of tetracycline $\mathrm{HCl}$ conditioning and fibrin-fibronectin system application in the treatment of buccal gingival recession with guided tissue regeneration. A 15 case-report. J Periodontol 66:313-320

10. Hallman M, Nordin T (2004) Sinus floor augmentation with bovine hydroxyapatite mixed with fibrin glue and later placement of nonsubmerged implants: a retrospective study in 50 patients. Int J Oral Maxillofac Implants 19:222-227

11. Moller JF, Peterson JK (1988) Efficacy of a fibrin sealant on healing of extraction wounds. Int J Oral Maxillofac Implants $17: 142-144$

12. Whitman DH, Berry RL, Green DM (1997) Platelet gel: an autologous alternative to fibrin glue with applications in oral and maxillofacial surgery. J Oral Maxillofac Surg 55:1294-1299

13. Borzini P, Mazzucco L (2005) Platelet gels and releasates. Curr Opin Hematol 12:473-479

14. Everts PA, Knape JT, Weibrich G, Schonberger JP, Hoffmann J, Overdevest EP et al (2006) Platelet-rich plasma and platelet gel: a review. J Extracorpor Technol 38:174-187

15. Anitua E, Andia I, Ardanza B, Nurden P, Nurden AT (2004) Autologous platelets as a source of proteins for healing and tissue regeneration. Thromb Haemost 91:4-15

16. Marx RE, Carlson ER, Eichstaedt RM, Schimmele SR, Strauss JE, Georgeff KR (1998) Platelet-rich plasma: growth factor enhancement for bone grafts. Oral Surg Oral Med Oral Pathol Oral Radiol Endod 85:638-646

17. Anitua E, Sanchez M, Orive G, Andia I (2007) The potential impact of the preparation rich in growth factors (PRGF) in different medical fields. Biomaterials 28:4551-4560

18. Arora NS, Ramanayke T et al (2009) Platelet-rich plasma: a literature review. Implant Dent 18(4):303-308

19. Marx RE (2004) Platelet rich plasma: evidence to support its use. J Oral Maxillofac Surg 64:489-496

20. Sunitha Raja V, Munirathnam Naidu E (2008) Platelet rich fibrin: evolution of a second generation platelet concentrate. Indian $\mathrm{J}$ Dent Res 19:42-46

21. Dohan DM, Choukroun J, Diss A, Dohan SL, Dohan AJ, Mouhyi $J$ et al (2006) Platelet-rich fibrin (PRF): a second-generation platelet concentrate. Part II: platelet-related biologic features. Oral Surg Oral Med Oral Pathol Oral Radiol Endod 101:e45-e50

22. Dohan DM, Choukroun J, Diss A, Dohan SL, Dohan AJ, Mouhyi $J$ et al (2006) Platelet-rich fibrin (PRF): a second-generation platelet concentrate. Part III: leucocyte activation: a new feature for platelet concentrates? Oral Surg Oral Med Oral Pathol Oral Radiol Endod 101:e51-e55

23. Choukroun J, Diss A, Simonpieri A, Girard MO, Schoeffler C, Dohan SL et al (2006) Platelet-rich fibrin (PRF): a second-generation platelet concentrate. Part IV: clinical effects on tissue healing. Oral Surg Oral Med Oral Pathol Oral Radiol Endod 101:e56-e60 